\title{
Rheumatic fever in a high incidence population: the importance of monoarthritis and low grade fever
}

\author{
J R Carapetis, B J Currie
}

\begin{abstract}
Aims-To describe the clinical features of rheumatic fever and to assess the Jones criteria in a population and setting similar to that in many developing countries.

Methods-The charts of 555 cases of confirmed acute rheumatic fever in 367 patients (97\% Aboriginal) and more than 200 possible rheumatic fever cases from the tropical "Top End" of Australia's Northern Territory were reviewed retrospectively.

Results-Most clinical features were similar to classic descriptions. However, monoarthritis occurred in $17 \%$ of confirmed non-chorea cases and $35 \%$ of unconfirmed cases, including up to 27 in whom the diagnosis was missed because monoarthritis is not a major manifestation. Only $71 \%$ and $25 \%$ of confirmed nonchorea cases would have had fever using cut off values of $38^{\circ} \mathrm{C}$ and $39^{\circ} \mathrm{C}$, respectively. In $17 \%$ of confirmed non-chorea cases, anti-DNase $B$ titres were raised but antistreptolysin $O$ titres were normal. Although features of recurrences tended to correlate with initial episodes, there were numerous exceptions.

Conclusions-Monoarthritis and low grade fever are important manifestations of rheumatic fever in this population. Streptococcal serology results may support a possible role for pyoderma in rheumatic fever pathogenesis. When recurrences of rheumatic fever are common, the absence of carditis at the first episode does not reliably predict the absence of carditis with recurrences. (Arch Dis Child 2001;85:223-227)
\end{abstract}

Keywords: rheumatic fever; monoarthritis; carditis; streptococcus

Acute rheumatic fever is an immunologically mediated sequel of group A streptococcal infection, which can affect a number of different tissues including heart, joint, and brain. The heart damage may be severe and permanent (rheumatic heart disease). Acute rheumatic fever and rheumatic heart disease are now rare in most affluent communities, but continue to affect millions of people and cause hundreds of thousands of deaths annually around the world, mostly in developing countries.

The most comprehensive recent descriptions of cases of acute rheumatic fever came from outbreaks in the United States, which were attributed to the appearance of mucoid strains of group A streptococci from particular serotypes. ${ }^{12}$ However, the epidemiology of group A streptococcal diseases, including rheumatic fever, differs between industrialised and developing countries. ${ }^{3}$ For example, in regions of the world where rheumatic fever is most common-developing countries and some indigenous populations in affluent countries-it occurs sporadically rather than in epidemics, and few cases may be attributed to highly virulent strains such as those held responsible for the United States outbreaks. ${ }^{3}$ One author has suggested that rheumatic fever in the United States and Britain became less severe over the last century, and that some manifestations common in the past (particularly severe carditis, subcutaneous nodules and chorea) are now rare. ${ }^{4}$ It is not clear if the disparity between industrialised and developing countries in rheumatic fever mortality and morbidity relates only to the incidence of disease, or perhaps also to differences in the clinical manifestations. ${ }^{5}$

The highest reported incidence rates of acute rheumatic fever in the world occur in the Aboriginal population of the northern region (Top End) of Australia's Northern Territory. ${ }^{6}$ The majority of this population lives in isolated, rural communities with poor housing and hygiene, and limited access to medical services; conditions which may be likened to those in many developing countries. ${ }^{7}$ We aimed to describe the clinical features of acute rheumatic fever in the Top End, and to compare these findings to classical descriptions and recent publications from the USA.

We looked in particular at joint manifestations and peak temperature. Mono- rather than polyarthritis is not specified in the Jones criteria, ${ }^{89}$ so qualifies only as arthralgia, a minor manifestation. Although the Jones criteria do not specify the minimum temperature to qualify as fever (a minor manifestation), the 1965 revision included the comment that the temperature usually exceeds $38^{\circ} \mathrm{C} .{ }^{9}$ However, the 1992 update stated that in most cases the temperature exceeds $39^{\circ} \mathrm{C}^{8}$; it was not clear why this change was made. Clinicians in the Northern Territory had the impression that individuals with acute rheumatic fever were sometimes presenting with monoarthritis and/or low grade fever, and that strict application of the Jones criteria was leading to under diagnosis. 


\section{Methods}

This study took place as part of a larger study in which a database was compiled of all known or suspected cases of acute rheumatic fever and rheumatic heart disease in the Top End. This report summarises the clinical features of all episodes of confirmed acute rheumatic fever on the database as of 31 March 1997: the conclusion of data collection for research purposes. The methods were described in earlier progress reports of epidemiological features. ${ }^{6}{ }^{10}$ Briefly, people with known or suspected past histories of acute rheumatic fever or rheumatic heart disease were ascertained from hospital and clinic records from 1976 to 1996. Clinical information was collected by chart review, clinical examination, and echocardiography as appropriate. Cases after 1994 were ascertained prospectively.

Because of incomplete ascertainment of earlier cases, the clinical details were compiled separately for cases from 1987 to 1996. To enable easy comparison with other studies, the clinical details were analysed separately for all episodes, for initial episodes (as the current Jones criteria apply only to the first diagnosis ${ }^{6}$ ), and excluding cases of chorea. As chorea may occur after a prolonged latent period following group A streptococcal infection, the other manifestations of rheumatic fever are less likely to be present. ${ }^{11}$ Therefore, the latter separation allows separate consideration of rheumatic fever cases that would be expected to have the features of acute disease. The clinical features of cases of Sydenham's chorea have been reported separately. ${ }^{12}$

Initial episodes of acute rheumatic fever were included only if they satisfied the 1992 update of the Jones criteria, and recurrences were diagnosed according to the criteria specified in the same report. ${ }^{8}$ Carditis was considered to be present if there was an organic cardiac murmur not previously documented or if there was clear evidence of pericarditis. In people with known rheumatic heart disease, carditis consisted of a new, worsened, or changed murmur, or cardiac failure in the presence of other evidence of active rheumatic inflammation. Polyarthritis was defined as swelling, or heat and obvious tenderness, affecting more than one joint; monoarthritis was also recorded, but classified as a minor criterion (arthralgia). We excluded cases of arthritis for which an alternative cause was found or that were treated as septic arthritis. Fever was considered to be present if the peak temperature was $\geqslant 38.0^{\circ} \mathrm{C}$. Other clinical features were as described. ${ }^{13}$

Because of the retrospective nature of the study, not all clinical information was available for all cases. In assessing the diagnostic validity of certain features, the number of patients with the feature is expressed as a proportion of those for whom information about the feature was available. The clinical features of a number of cases of possible rheumatic fever that did not satisfy the Jones criteria were considered separately.

All statistical calculations were performed using the Stata Release 5 package (Stata
Table 1 Demographic features of people with acute rheumatic fever

\begin{tabular}{|c|c|c|c|c|}
\hline \multirow[b]{2}{*}{ Feature } & \multicolumn{2}{|c|}{ All cases } & \multicolumn{2}{|c|}{$1987-1996$} \\
\hline & $\begin{array}{l}\text { No. } \\
\text { cases }\end{array}$ & $\begin{array}{l}\text { No. } \\
\text { people }\end{array}$ & $\begin{array}{l}\text { No. } \\
\text { cases }\end{array}$ & $\begin{array}{l}\text { No. } \\
\text { people }\end{array}$ \\
\hline \multicolumn{5}{|l|}{ Sex } \\
\hline Female & 336 & 221 & 166 & 129 \\
\hline Male & 219 & 146 & 137 & 103 \\
\hline \multicolumn{5}{|l|}{ Ethnicity } \\
\hline Aboriginal & 543 & 355 & 297 & 226 \\
\hline Non-Aboriginal & 12 & 12 & 6 & 6 \\
\hline \multicolumn{5}{|l|}{ Residence* } \\
\hline Urban & 82 & 52 & 40 & 31 \\
\hline Rural & 472 & 314 & 262 & 200 \\
\hline
\end{tabular}

Relative risks 1987-1996 of having acute rheumatic fever: Aboriginal compared to non-Aboriginal 124.2 (95\% CI 55.2 to 279.3); Aboriginal female compared to Aboriginal male 1.3 (95\% CI 1.0 to 1.7 ); Aboriginal rural compared to Aboriginal urban 3.3 (95\% CI 2.2 to 5.0 ).

^Residence unknown for one person.

Corporation, Texas). Mean values are presented with standard deviations (SD), and median values are presented with interquartile ranges (IQR). Categorical data were compared using $\chi^{2}$ analysis. The proportions of cases of acute rheumatic fever presenting in the two seasons in the Northern Territory were compared using the two sample test of proportions. Numerators for relative risks (calculated as risk ratios), 95\% confidence intervals (95\% CI), and two tailed Fisher's exact test $\mathrm{p}$ values for associations between acute rheumatic fever and demographic features were taken as individuals with at least one episode of acute rheumatic fever (rather than total cases, which would have overcounted people with recurrences). Denominators came from revised census estimates; the average population estimates for the Top End during 1987 to 1996 were 29358 Aboriginal people (14 752 males, 14605 females) and 96800 non-Aboriginal people (51 412 males, 45388 females), with $71 \%$ of the Aboriginal people living in rural settings.

\section{Results}

There were 555 cases of confirmed acute rheumatic fever in 367 people ( 30 who had a first documented episode of rheumatic fever after a prior diagnosis of rheumatic heart disease); 303 cases in 232 people from 1987 to 1996 . Table 1 shows the demographic features, highlighting the increased risk for Aboriginals, females, and those with rural residence. Figure 1 shows the

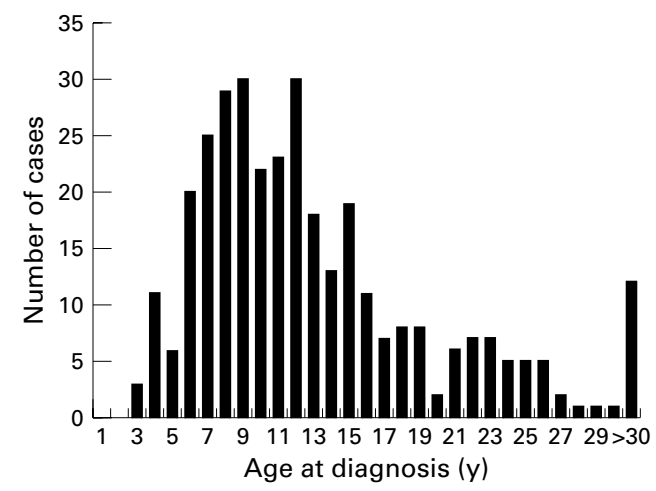

Figure 1 Age at diagnosis of acute rheumatic fever: first episodes only $(n=337)$. See text for explanation of cases over 30 years of age. 


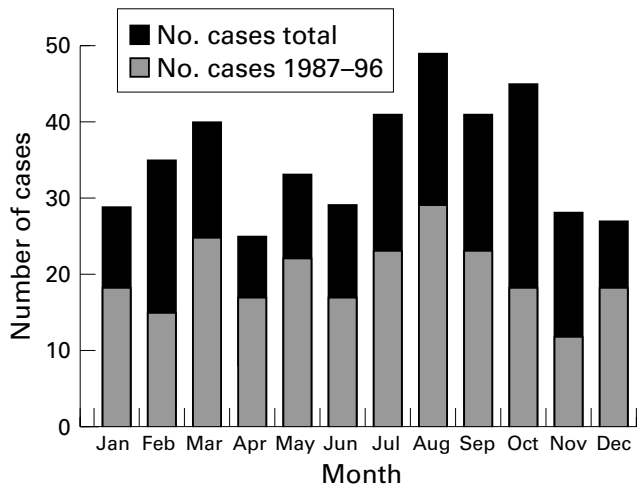

Figure 2 Cases of confirmed acute rheumatic fever by month of diagnosis (non-chorea but including chorea with evidence of carditis or arthritis). Total of 422 cases where month of diagnosis known (237 cases 1987-1996).

age at diagnosis of the 337 first episodes. The median age (IQR) at first diagnosis was 11.9 years (8.6-16.4) for all episodes, and 12.9 years (9.2-19.1) excluding those with chorea. Twelve people were reported to have had their first episode of acute rheumatic fever after age 30 years. The oldest definite first episode occurred at age 36 years, and the oldest definite recurrence at age 59 years. A further six people aged between 31 and 62 years had first episodes satisfying the revised Jones criteria, with no confirmed alternative diagnoses, but the treating physicians were reluctant to diagnose acute rheumatic fever in these patients solely because of age.

There was a tendency for increased numbers of cases between July and September (fig 2). There are two main seasons in this region: the "wet" from October to March, and the "dry" from April to September. Excluding pure chorea, for the period 1987-1996, there were 131 cases during the dry season and 106 during the wet season $(55.3 \%$ of cases during the dry season, $95 \%$ CI 48.9 to $61.6 ; \mathrm{p}=0.10$ ).

Table 2 summarises the clinical features of all cases and the 337 first episodes. The features of cases from 1987 to 1996 were almost identical to those of all cases (data not shown).

ARTHRITIS

Contrary to many previous descriptions, we found that monoarthritis was a common joint manifestation. Of 377 cases of non-chorea acute rheumatic fever where joint manifestations were documented, 202 (54\%) had polyarthritis, $63(17 \%)$ had monoarthritis, 74 $(20 \%)$ had arthralgia without arthritis, and 38 $(10 \%)$ had no joint symptoms. Fifty per cent of monoarthritis involved the knee, $24 \%$ the ankle, and the remainder the elbow, hip, or shoulder. Monoarthritis was present in 75 of $216(35 \%)$ cases of possible acute rheumatic fever (not satisfying the Jones criteria). Twenty seven $(13 \%)$ of these would have satisfied the criteria if monoarthritis was a major manifestation, and 15 later had a confirmed episode of rheumatic fever or developed rheumatic heart disease, suggesting that the initial episode was indeed rheumatic fever.

FEVER

Low grade fever was also a common manifestation in this series. The peak temperature was recorded in 305 cases of confirmed acute rheumatic fever (excluding chorea). Using cut offs of $\geqslant 37.5^{\circ} \mathrm{C}$ or $\geqslant 38.0^{\circ} \mathrm{C}, 270(89 \%)$ and 217 $(71 \%)$ patients, respectively, would have had "fever" as a minor manifestation. However a cut off of $\geqslant 39.0^{\circ} \mathrm{C}$ would have resulted in only 76 (25\%) having fever. The corresponding percentages with fever of 186 first episodes were $90 \%, 73 \%$, and $25 \%$, respectively. Of 109 possible cases (not satisfying the Jones criteria) with temperatures $\geqslant 37.5^{\circ} \mathrm{C}, 34$ had temperatures $37.5-37.9^{\circ} \mathrm{C}$ (that is, less than $38^{\circ} \mathrm{C}$, the cut-off for fever used in this report). Of these, $14(41 \%)$ would have satisfied the Jones criteria if the definition of fever was $\geqslant 37.5^{\circ} \mathrm{C}$, and seven later had confirmed rheumatic fever or developed rheumatic heart disease.

Table 2 Clinical features of definite cases of acute rheumatic fever

\begin{tabular}{|c|c|c|c|c|}
\hline Feature & All cases & All cases (non-chorea) & First episodes & First episodes (non-chorea) \\
\hline Number of cases & 555 & 397 & 337 & 238 \\
\hline Number of people & 367 & 277 & 337 & 238 \\
\hline Carditis & $292(55)$ & $255(66)$ & $174(55)$ & $153(67)$ \\
\hline Cardiac failure & $57(11)$ & $57(15)$ & $29(9)$ & $29(13)$ \\
\hline Pericarditis & $21(4)$ & $20(5)$ & $9(3)$ & $8(4)$ \\
\hline \multicolumn{5}{|l|}{ Arthritis } \\
\hline Total & $284(55)$ & $272(72)$ & $182(58)$ & $174(78)$ \\
\hline Polyarthritis & $217(42)$ & $209(55)$ & $148(47)$ & $143(64)$ \\
\hline Monoarthritis & $67(13)$ & $63(17)$ & $34(11)$ & $31(14)$ \\
\hline Chorea & $158(28)$ & - & $99(31)$ & - \\
\hline Erythema marginatum & $3(1)$ & $3(1)$ & $3(1)$ & $3(1)$ \\
\hline Nodules & $3(1)$ & $3(1)$ & $3(1)$ & $3(1)$ \\
\hline Arthralgia & $149(29)$ & $133(36)$ & $72(23)$ & $62(28)$ \\
\hline Prolonged PR on ECG & $115(35)$ & $\begin{array}{l}110(41) \\
\text { Mean }(S D)^{*}\end{array}$ & $71(34)$ & $\begin{array}{l}69(41) \\
\text { Mean }(S D) *\end{array}$ \\
\hline Peak temperature $\left({ }^{\circ} \mathrm{C}\right)$ & - & $38.3(0.8)[305]$ & - & $38.3(0.7)[186]$ \\
\hline Peak ESR $(\mathrm{mm} / \mathrm{h})$ & - & $88(32)[325]$ & - & 87 (32) [192] \\
\hline Peak CRP (IU) & - & $144(117)[71]$ & - & $119(93)[47]$ \\
\hline Peak WCC $\left(\times 10^{9} / 1\right)$ & - & $12.8(4.6)[323]$ & - & $13.0(4.5)[187]$ \\
\hline Peak ASOT (IU) & - & 569 (406) [336] & - & $592(443)[197]$ \\
\hline Peak ADBT (IU) & - & $1822(1030)[275]$ & - & 1967 (1043) [162] \\
\hline
\end{tabular}

Numbers in parentheses represent the percentage of people for whom the information was available who had that feature.

$\star$ Numbers in square brackets represent the number of cases for which the information was available for that feature. Temperature, acute phase reactants, and streptococcal serology results are presented only for the non-chorea cases as these are often normal in chorea.

ECG, electrocardiogram; ESR, erythrocyte sedimentation rate; CRP, C reactive protein; WCC, white blood cell count; ASOT, antistreptolysin O titre; ADBT, anti-DNase B titre. 
EVIDENCE OF GROUP A STREPTOCOCCAL INFECTION

We found that the anti-DNase B titre was usually raised, whereas the antistreptolysin $\mathrm{O}$ titre was frequently normal. In all cases, raised titres of at least one antistreptococcal antibody were documented. The mean anti-DNase B titre was about three times higher than the mean antistreptolysin $\mathrm{O}$ titres in non-chorea cases (table 2). Table 3 shows the proportion of people with confirmed acute rheumatic fever who had raised streptococcal serology results; antiDNase B titres were raised in almost all cases where they were done, whereas the antistreptolysin $\mathrm{O}$ titres were not raised in $14 \%$ of nonchorea cases. Moreover, the evidence of recent streptococcal infection relied solely on raised anti-DNase B titres in $17 \%$ of non-chorea cases where both serological tests were done. The 51 cases with raised anti-DNAse B titres and normal antistreptolysin $\mathrm{O}$ titres occurred in 44 people. Thirty six of these 44 people $(82 \%)$ at some other time had a diagnosis of confirmed rheumatic heart disease or confirmed acute rheumatic fever; in five of the remaining eight people the diagnosis of acute rheumatic fever was considered certain. Therefore, the diagnosis of acute rheumatic fever could have been considered uncertain in only three of 44 people $(7 \%)$ in whom raised anti-DNase B titres but normal antistreptolysin $\mathrm{O}$ titres were used as evidence of recent group A streptococcal infection. In 168 cases of acute rheumatic fever a throat swab was recorded as being done, but only seven (4\%) were positive for group A streptococci; this reduced to $2 \%$ in the recent period. Only 34 people were noted to have a recent sore throat, although this was not recorded consistently.

RECURRENCES

A total of 218 of $555(39.2 \%)$ cases of acute rheumatic fever occurred in 107 people who had previously been diagnosed with rheumatic fever or rheumatic heart disease. The clinical features of first episodes and recurrences were very similar (table 1), except that arthritis and polyarthritis were diagnosed more commonly in first episodes ( $78 \%$ and $64 \%$, respectively) than recurrences $(63 \%$ and $43 \%)\left(\chi^{2}=10.4\right.$, $\mathrm{p}=0.001$ for arthritis and $\chi^{2}=17.6$, $\mathrm{p}<0.001$ for polyarthritis). By contrast, arthralgia was less common in first episodes $(28 \%)$ than recurrences $(46 \%)\left(\chi^{2}=12.5\right.$, $\mathrm{p}<0.001)$, possibly reflecting the fact that, by definition, recurrences but not first episodes may be diagnosed in the absence of major criteria. ${ }^{6}$

Table 3 Streptococcal serology results in episodes of confirmed acute rheumatic fever

\begin{tabular}{lll}
\hline Serological test* & Non-chorea (\%) & Chorea (\%) \\
\hline ASOT elevated & $314 / 367(86 \%)$ & $58 / 76(76 \%)$ \\
ADBT elevated & $299 / 301(99 \%)$ & $54 / 55(98 \%)$ \\
Both elevated & $240 / 293(82 \%)$ & $42 / 55(76 \%)$ \\
Only ASOT elevated & $2 / 293(1 \%)$ & $0 / 55(0 \%)$ \\
Only ADBT elevated & $51 / 293(17 \%)$ & $12 / 55(22 \%)$
\end{tabular}

^ASOT, antistreptolysin O titre; ADBT, anti-DNase B titre ASOT $\geqslant 256$ IU considered raised; ADBT $\geqslant 300 \mathrm{IU}$ considered raised. Results are cited for all episodes for which the specified serology result(s) were available.
Table 4 Concordance of major clinical features at recurrences with features present at first episode of acute rheumatic fever

\begin{tabular}{|c|c|c|c|}
\hline \multirow{2}{*}{$\begin{array}{l}\text { Feature at } \\
1 \text { st episode }\end{array}$} & \multicolumn{2}{|c|}{$\begin{array}{l}\text { Feature at any } \\
\text { recurrence }\end{array}$} & \multirow{2}{*}{$\begin{array}{l}\text { Relative risk } \\
(95 \% C I)^{\star}\end{array}$} \\
\hline & + & - & \\
\hline Carditis & & & $1.3(0.98$ to 1.8$)$ \\
\hline+ & 39 & 14 & \\
\hline- & 28 & 22 & \\
\hline Arthritis† & & & $2.0(1.4$ to 3.0$)$ \\
\hline+ & 41 & 12 & \\
\hline- & 18 & 29 & \\
\hline Chorea & & & $12.2(4.6$ to 32.2$)$ \\
\hline+ & 28 & 11 & \\
\hline - & 4 & 64 & \\
\hline
\end{tabular}

${ }^{\star}$ Risk ratio of feature at any recurrence if feature present at first episode of acute rheumatic fever (includes only patients with at least one recurrence; total cases differ with each feature because of missing data).

†Arthritis includes polyarthritis and monoarthritis.

The clinical features of recurrences correlated with the features at the initial episode, especially for chorea (table 4). However, 56\% of patients without carditis at the initial episode had carditis with at least one recurrence, and arthritis occurred subsequently in $38 \%$ of those who did not have it initially.

\section{Discussion}

There were few differences in the clinical features of acute rheumatic fever in the Aboriginal population compared to classic descriptions, ${ }^{14}{ }^{15}$ with the exception of the relatively common occurrences of monoarthritis and low grade fever. We were unable to determine the sensitivity, specificity, or predictive values of the Jones criteria because of the lack of a "gold standard" for diagnosis, and because we did not prospectively study all possible cases (for example, those with joint symptoms) who were eventually diagnosed with a different condition. However, we did identify a number of cases with monoarthritis and low grade fever in which the diagnosis was missed by strict application of the Jones criteria.

In other countries, arthritis in rheumatic fever has been described as occurring in "one or more joints", ${ }^{16}$ and a prospective study in India found that $13 \%$ of cases of arthritis in rheumatic fever were monoarticular. ${ }^{17}$ Because of the retrospective nature of our study, we could not determine the proportion of children who received anti-inflammatory medication prior to presentation, which may have prevented the progression of arthritis to involve other joints or reduced the temperature. However, the use of these medications is not common in many rural Aboriginal communities. Moreover, our findings reflect the clinical setting of many developing countries, where minimal information may be available about prior medication or other aspects of the history before presentation to health services.

In populations with high rates of rheumatic fever, where the consequences of missed diagnosis may outweigh those of over diagnosis, the positive predictive value of less stringent criteria for rheumatic fever diagnosis may be acceptable. After excluding the major differential diagnoses of fever and arthritis in northern Australia-arboviral infections and septic 
arthritis - clinicians in our region now consider large joint monoarthritis a major manifestation and any fever $\geqslant 37.5^{\circ} \mathrm{C}$ a minor manifestation of the Jones criteria. Clearly, this increases the sensitivity but decreases the specificity of the criteria, which is inappropriate for countries with low incidences of acute rheumatic fever. However, if our findings are replicated in other populations and with prospective studies, clinicians in similar settings to ours may choose to interpret the criteria in the same way. Alternatively, calls for two levels of Jones criteria may be appropriate: the present or perhaps even a stricter version for countries where rheumatic fever is now uncommon, and separate criteria for countries with high rates of rheumatic fever, possibly incorporating monoarthritis and recommendations about low grade fever. These uncertainties highlight the need for a definitive diagnostic test for rheumatic fever.

Anti-DNase B titres were raised in almost all cases of acute rheumatic fever, whereas antistreptolysin $\mathrm{O}$ titres were normal in about one sixth of cases. Raised anti-DNase B titres may reflect the high background amounts of streptococcal antibodies in this population, presumably related to high prevalences of pyoderma. ${ }^{18}$ However, based on the clinical features and a later history of further episodes of acute rheumatic fever or rheumatic heart disease, it seems likely that the majority of cases with normal antistreptolysin $\mathrm{O}$ titres were true cases of acute rheumatic fever. The antistreptolysin $\mathrm{O}$ response is weak after skin infection with group A streptococci compared to throat infection, whereas the anti-DNase $B$ response is strong after infection at either site. ${ }^{19}$ This suggests either that the antistreptolysin $\mathrm{O}$ response of many Aboriginal people to throat infection with group A streptococci was surprisingly poor, or that the site of their preceding infection was not the throat. We have previously raised the possibility that pyoderma may be implicated in some cases of rheumatic fever. ${ }^{20}$ There is an urgent need to clarify this issue, as it has important implications for primary prevention in developing countries.

The tendency for the clinical features of recurrent acute rheumatic fever to mimic the features of the first episode has long been known. ${ }^{21}{ }^{22}$ Although this is also true in the Aboriginal population, there are a substantial number of people who developed features with recurrences that were not evident at the previous episode. The retrospective nature of the study sometimes made it difficult to be certain that mild carditis was not being underdiagnosed in earlier episodes, but the practical implication of this finding is that the absence of carditis during the initial episode of rheumatic fever may not be helpful in determining the risk of later episodes of carditis or later development of rheumatic heart disease. Furthermore, the difficulties of diagnosing subtle carditis and the importance of ascertaining the presence of valve damage support our policy of recommending echocardiograms around six months after all episodes of acute rheumatic fever. We found that in cases of chorea, 58\% eventually developed rheumatic heart disease despite most not having evidence of acute carditis with their chorea. ${ }^{12}$

The high rate of recurrent acute rheumatic fever in the Aboriginal population-about $40 \%$ of all episodes-reflects the lack of success of present secondary prophylaxis regimens. Adherence to the recommended schedule in this region (1.2 million units of benzathine penicillin $\mathrm{G}$ every month) is poor in many communities, and has been the stimulus for the institution of a register based acute rheumatic fever and rheumatic heart disease control programme.

We thank the doctors, nurses, and Aboriginal health workers of Top End hospitals and community clinics for providing information about patients, and Dr Charles Kilburn for performing echocardiography. Professor John Mathews provided valuable advice and critically reviewed the manuscript. Funding support was provided by the National Health and Funding support was provided by the National Health and tion of Australia.

1 Veasy LG, Tani LY, Hill HR. Persistence of acute rheumatic fever in the intermountain area of the United States. F Pediatr 1994;124:9-16.

2 Kaplan EL, Johnson DR, Cleary PP. Group A streptococcal serotypes isolated from patients and sibling contacts during the resurgence of rheumatic fever in the United States in the mid-1980s. F Infect Dis 1989;159:101-3.

3 Carapetis JR, Currie BJ, Kaplan EL. Epidemiology and prevention of group A streptococcal infections: acute respiratory tract infections, skin infections, and their sequelae at the close of the twentieth century. Clin Infect Dis 1999;28:205-10.

4 English PC. Rheumatic fever in America and Britain: a biological, epidemiological and medical history. New Brunswick, NJ: Rutgers University Press, 1999.

5 Gersony WM. Rheumatic fever [book review]. FAMA 2000; 284:892-3.

6 Carapetis JR, Currie BJ. Clinical epidemiology of rheumatic fever and rheumatic heart disease in tropical Australia. $A d v$ Exp Med Biol 1997;418:233-6.

7 Munoz E, Powers JR, Nienhuys TG, Mathews JD. Social and environmental factors in 10 Aboriginal communities in the Northern Territory: relationship to hospital admissions of children. Med F Aust 1992;156:529-33.

8 Special Writing Group of the Committee on Rheumatic Fever, Endocarditis, and Kawasaki Disease of the Council on Cardiovascular Disease in the Young of the American Heart Association. Guidelines for the diagnosis of acute rheumatic fever: Jones criteria, 1992 update. $\mathcal{F} A M A$ 1992; 268:2069-73

9 Stollerman GH, Markowitz M, Taranta A, et al. Committee report: Jones criteria (revised) for guidance in the diagnosis of rheumatic fever. Circulation 1965;32:664-8.

10 Carapetis JR, Wolff DR, Currie BJ. Acute rheumatic fever and rheumatic heart disease in the Top End of Australia's and rheumatic heart disease in the Top End of A

11 Taranta A, Stollerman GH. The relationship of Sydenham's chorea to infection with group A streptococci. Am $\mathcal{F} \mathrm{Med}$ 1956;20:170-5.

2 Carapetis JR, Currie BJ. Rheumatic chorea in northern Australia: a clinical and epidemiological study. Arch Dis Child 1999;80:353-8.

13 World Health Organization. Rheumatic fever and rheumatic heart disease-report of a WHO study group. World Health Organ Tech Rep Ser (764) 1988:1-58.

14 Jones TD. The diagnosis of acute rheumatic fever. $7 A M A$ 1944;126:481-4.

15 Stollerman GH. Rheumatic fever and streptococcal infection. New York: Grune \& Stratton, 1975.

16 Jamal M, Abbas KA. Clinical profile of acute rheumatic fever in children. $\mathcal{F}$ Trop Pediatr 1989;35:10-13.

17 Sanyal SK, Thapar MK, Ahmed SH, Hooja V. The initial attack of acute rheumatic fever during childhood in India: a prospective study of the clinical profile. Circulation 1974; 49:7-12.

18 Van Buynder PG, Gaggin JA, Martin D, et al. Streptococcal nfection and renal disease markers in Australian Aboriginal children. Med f A ust 1992;156:537-40.

19 Kaplan EL, Anthony BF, Chapman SS, et al. The influence of site of infection on the immune response to group A streptococci. F Clin Invest 1970;49:1405-14.

20 Carapetis JR, Currie BJ. Group A streptococcus, pyoderma, and rheumatic fever [letter]. Lancet 1996;347:1271-2.

21 Taranta A. Factors influencing recurrent rheumatic fever. Ann Rev Med 1967;18:159-72.

22 Feinstein AR, Spagnuolo M. Mimetic features of rheumatic fever recurrences. N Engl f Med 1960;262:533-40. 